\title{
The Teacher as an Island? A Mixed Method Study on the Relationship Between
}

\section{Autonomy and Collaboration}

Katrien Vangrieken ${ }^{\mathrm{a}} \&$ Eva Kyndt ${ }^{\mathrm{ab}}$

${ }^{a}$ University of Leuven, Centre for Research on Professional Learning \& Development, Corporate Training and Lifelong Learning

Dekenstraat 2 - Box 3772

3000 Leuven

Belgium

${ }^{b}$ University of Antwerp, Training and Education Sciences, Faculty of Social Sciences

Sint-Jacobsstraat 2

2000 Antwerp

Belgium

Corresponding author: Katrien Vangrieken,

e-mail address: katrien.vangrieken@kuleuven.be

telephone number: +3216320967

ORCID

Katrien Vangrieken: 0000-0003-0344-2878

Eva Kyndt: 0000-0002-6755-4409 


\section{The Teacher as an Island? A Mixed Method Study on the Relationship Between Autonomy and}

Collaboration

This study assessed how teachers understand and value autonomy, collaboration, and the relationship between both. Quantitative analyses $\left(N_{I}=1610, N_{2}=1408\right)$ included a multilevel SEM model and identifying teacher profiles based upon perceived autonomy (curricular, didactical-pedagogical) and autonomy attitude (individualistic/reactive, collaborative/reflective). Interviews $(N=17)$ were analysed using qualitative content analysis. Three teacher profiles were identified: autonomous collaborative, autonomous individualistic, and low curricular autonomy collaborative. Teachers in the first profile reported most collaboration. Results demonstrate the need to take the interaction between autonomy and attitude into account. However, small effect sizes and qualitative results indicate that other factors play an important role. Didactical-pedagogical autonomy should be split up into contentrelated and classroom teaching-related aspects (demonstrating higher sensitivity to external influences). Moreover, while quantitative results demonstrate a unified collaborative attitude, qualitative findings indicate that openness towards deep-level collaboration differs depending on the domain of autonomy. Finally, besides individual autonomy, autonomy at the level of collaboration is influential.

Keywords: Teacher autonomy; Collaboration; Reactive attitude; Reflective attitude 
Schools have a long history of teacher isolation, wherein teachers led a solitary existence as privately practicing professionals in their classrooms (Gajda \& Koliba, 2008; Street \& Licata, 1989). However, ambitious aims of educational trends (e.g., focus on $21^{\text {st }}$ century skills, increasing classroom diversity due to inclusive education) put high levels of pressure on individual teachers, placing a burden on their wellbeing and classroom practice. Solitary work of teachers has been argued to no longer suffice to tackle these challenges and teacher collaboration has been proposed as the key to high quality education. Collaboration results in teachers feeling supported and decreased feelings of isolation, fostering teachers' wellbeing and teaching effectiveness (Sehgal, Nambudiri, \& Kumar Mishra, 2017; Siciliano, 2016; Simbula, Guglielmi, \& Schaufeli, 2011). Moreover, teachers' professional development initiatives have shifted from a focus on individual teachers to collaborative approaches, which is for example demonstrated in the rise of formats such as professional learning communities (Author(s), 2017b; Horn, Garner, Delinger Kane, \& Brasel, 2017). Collaboration provides learning opportunities, teachers exchange expertise, leading to improved instructional skills and ultimately instructional quality (Gore et al., 2017).

However, the question remains as to whether this collective mind-set has actually penetrated teachers' practice and beliefs about their job. Teacher autonomy has remained a strongly desired and valued workplace condition that is related to teachers' professional status and job satisfaction (Kelchtermans, 2006; Strong \& Yoshida, 2014). Teachers' common-sense beliefs tend to equate autonomy to working individually and independently, which may hamper the rise of a true collaborative culture in schools (Gajda \& Koliba, 2008; Moomaw, 2005; Street \& Licata, 1989). Hence, installing a collective mind-set among teachers requires a shift in teachers' understanding of autonomy, away from a focus on independence and non-reliance. Although previous research referred to different forms of autonomy, mostly building on the work of Hargreaves (1993) (e.g., Clement \& Vandenberghe, 2000; Kelchtermans, 2006), attention for what it actually means for teachers to work autonomously or teachers' conceptions of autonomy is more limited. In this study, the focus is on investigating how teachers' understanding of autonomy can help understand the potentially tensed relationship between autonomy and collaboration. To fully grasp this relationship, a mixed methods design was used. The quantitative part combined variable-centred and person-centred analyses. The 
latter allows identifying how teachers' mind-sets and conceptions manifest in practice. By identifying autonomy profiles among teachers (based upon perceived autonomy and attitude towards autonomy), this study aimed to discern different autonomy interpretations and assess how they relate to reported levels of collaboration. A qualitative study was set up to gain more fine-grained understanding of teachers' conceptions of autonomy and collaboration and to explore other factors that can help explain the relationship between teacher autonomy and their willingness to collaborate. Based upon purposive sampling a diversified sample of teachers was invited for an interview.

\section{Teacher Autonomy: Capturing an Elusive Concept}

The teacher autonomy framework developed by Author(s) (2017a) was used to help understand the relationship between autonomy and collaboration. Teacher autonomy has been defined in different ways and authors tend to disagree on its meaning (e.g., Strong \& Yoshida, 2014; Wilches, 2007). Differences in the interpretation of autonomy mostly emanate from two sources: (1) autonomy can refer to different domains of teachers' practice and (2) different attitudes towards autonomy can be distinguished (Author(s), 2017a).

\section{Domains of Teacher Autonomy}

Autonomy can relate to different domains of teachers' job, such as teaching and assessment, curriculum development, professional development, and school functioning (Friedman, 1999; Wilches, 2007). In this study, the focus is on classroom autonomy rather than participation in decision-making at the school-level. Teacher autonomy is often constrained to the classroom and while teachers regret that they experience less autonomy regarding organisational activities and school-level policy, they find this far more acceptable than lacking autonomy regarding day-to-day classroom activities (Firestone \& Pennel, 1993; Pearson \& Moomaw, 2005; Strong \& Yoshida, 2014; Wilches, 2007). Classroom autonomy can be defined as "the ability to control daily schedules, to teach as one chooses, to have freedom to make decisions on instruction, and to generate ideas about curriculum" (Husband \& Short, 1994, p. 60). 
This definition indicates that classroom autonomy still refers to different domains of teachers' job. Author(s) (2017a) distinguished between didactical-pedagogical and curricular autonomy. Didactical-pedagogical autonomy refers to freedom regarding lesson preparation, choice and use of textbooks, choice of student assignments, student evaluation, teaching methods and strategies, use of time and planning, and managing student behaviour. Curricular autonomy includes autonomy regarding lesson content, flexible implementation of the curriculum within the teacher's own classroom, and setting goals for students. Overall, didactical-pedagogical autonomy is perceived as highest as teachers' experienced classroom autonomy mainly relates to teaching or instructional methods, the selection of school textbooks, the basis on which students are grouped together and student assessment (Desurmont, Forsthuber, \& Oberheidt, \& 2008; Strong \& Yoshida, 2014).

\section{Autonomy Attitudes}

The essence of autonomy - what it means to be autonomous - has been described in different ways. As argued by Yu-Hong and Ting (2012):

What seems like autonomy to one teacher may seem like isolation to another. One teacher may view autonomy as a means to gain substantial freedom from interference or supervision, while another teacher may view it as the freedom to develop collegial relationships and accomplish tasks that extend beyond classrooms. (p. 1046)

This distinction in two interpretations of autonomy reflected in the phrasing of freedom from and freedom to is in line with the attitudes towards autonomy described by Author(s) (2017a).

Reactive attitude. When endorsing a reactive attitude towards autonomy, the latter is equated to independence and individual work. In reactive autonomy definitions, classroom autonomy emanates from and is supported by the structure of school systems. Teachers work alone in their classrooms and have extensive discretionary power within the boundaries thereof which leads them to be restricted to and protected by a state of classroom isolation excluding interference and close examination of their classroom practice (Bidwell, 1965; Gajda \& Koliba, 2008; Goddard, Goddard, \& Tschannen-Moran, 2007; Hargreaves, 2010; Westheimer, 2008). In these solitary settings - described by Lortie (1975) as the egg-crate structure of schools - interdependence is minimised (Firestone \& Herriot, 1982). Here, 
autonomy is thus defined in terms of teachers working in isolation in a classroom, in an independent and non-collaborative way, and being resistant to external influences, even when this is detrimental (Chirkov, Ryan, Kim, \& Kaplan, 2003; Willner, 1990). Hence, this indicates an individualistic attitude towards autonomy, wherein autonomy becomes a form of individualism. This builds on norms of noninterference and non-reliance, which withhold teachers from interfering with (or being influenced by) the work of colleagues (Parish \& Arends, 1983).

Reflective attitude. A reflective attitude stems from Self-Determination theory, focusing on personal choice and people wanting to possess agency, to feel that they themselves are the origin of their behaviour (Author(s), 2017a; Deci \& Ryan, 1991). It refers to experiencing one's behaviour as willingly enacted, deriving from an internal locus of causality, and fully endorsing one's actions and the values these represent (Chirkov et al., 2003; DeCharms, 1968). This does not exclude external interference or dependencies as it takes school stakeholders' needs and necessary conditions for success into account (Wilches, 2007). From a reflective perspective, autonomous teachers are aware of the inevitable (inter)dependence and are able to handle this situation by making personal choices based upon an awareness of their needs and values (Gavrilyuk et al., 2014; Hodgins, Koestner \& Duncan, 1996). The focus is on the teacher as a self-governing professional making self-determined choices and classroom autonomy resides from the teacher him- or herself and his or her freedom to act in a self-directed manner. The latter allows openness for self-selected external influences and interdependence in teachers' classroom practice. Hence, when endorsing a reflective attitude, autonomy is not equated to a form of individualism but it is combined with openness towards collaboration and thus a collaborative rather than an individualistic attitude. From this perspective, teachers as autonomous professionals understand the potential added value of external input rather than desiring complete independence.

\section{Teacher Collaboration: Collaborative Activities and Level of Depth}

Collaboration can be defined as task-related cooperative actions with colleagues (Kelchtermans, 2006). Different collaborative actions can be distinguished with varying levels of depth (Author(s), 2015). Little (1990) described a continuum of collaboration characterised by 
growing levels of interdependence: Storytelling and scanning for ideas at the independence end of the continuum, followed by aid and assistance, sharing, and joint work as being characterised by the highest level of interdependence. De Vries, Jansen, and van de Grift (2013) described two types of collaborative activities. Exchange activities include exchanging ideas, materials, and learning experiences, talking about classroom practice, and discussing educational theories and innovation. Professional collaboration refers to activities such as developing teaching and test materials and preparing lessons with colleagues, team teaching, and experimenting with teaching methods with colleagues. Exchange activities can be positioned on the more independent end of Little's (1990) continuum while professional collaboration tends to be characterised by higher levels of interdependence.

In practice, teacher collaboration often appears to be restricted to the discussion of practical affairs (Plauborg, 2009). Teachers hardly engage in collaborative activities that go beyond talking or discussing ideas and materials, planning teaching activities, the pace and content of teaching, and the nature and content of student evaluation or assessment (Cheng \& Ko, 2009; Kwakman, 2003; Visscher \& Witziers, 2004). However, deep-level collaboration including an exchange, discussion, and confrontation of underlying beliefs is essential for realising actual school improvement and teacher learning (Clement \& Vandenberghe, 2000; Doppenberg, den Brok, \& Bakx, 2012; Levine \& Marcus, 2010; Plauborg, 2009). Deep-level collaboration includes putting the daily practice into question and discussing the didactics of teaching, problems in teachers' daily practice, and observing and discussing each others' functioning (Cheng \& Ko, 2009; Visscher \& Witziers, 2004). This tends to be difficult to accomplish because it leads to an increased chance of the occurrence of disagreements while teachers usually prefer harmony and congeniality when interacting (Levine \& Marcus, 2007; Ohlsson, 2013). Hence, deep-level collaboration does not only require exchange activities and professional collaboration, but also an openness to constructively discuss disagreements. While constructive conflict has long been identified as an important process in research on collaboration in various types of industry and organisations (e.g., Tjosvold \& Yu, 2007), there is limited attention for disagreement and conflict as positive aspects of collaboration in research in the context of teachers. However, although teachers tend to be described as conflict-avoidant (Achinstein, 2002; Ohlsson, 2013), 
education was also described as a contested domain in which complete consensus on values, visions, and pedagogical beliefs seems unlikely, and even undesirable (Lavié, 2006). Constructive conflict - or openly and constructively discussing professional disagreements - is thus a desirable collaborative process that is required for deep-level collaboration.

\section{The Relationship Between Teacher Autonomy and Collaboration}

The fact that both autonomy and collaboration can take different forms and shapes can help explain the ambiguous relationship between both (Author(s), 2015). First of all, teachers' attitude towards autonomy may influence the relationship. The main difference between a reactive and a reflective attitude includes the degree of openness towards external influences. When endorsing a reactive attitude focused on independence, collaboration may be perceived by teachers as threatening their autonomy, resulting in a negative attitude towards interdependent collaboration (Author(s), 2017a; Moolenaar, 2010; O'Reilly, Chatman, \& Caldwell, 1991). The conception of autonomy as freedom from interference that can be found in a reactive attitude seems to exclude collaboration. Definitions including a reflective attitude appear to open up possibilities for collaborative work as they do not perceive autonomy as opposite to (inter)dependence and collaboration. As argued by Author(s) (2017a), teachers can feel autonomous while they collaborate and they can experience a lack of autonomy when working in isolation if the latter is not a personal choice but for example a side effect of administrative or organisational limitations. Hence, a reflective autonomy attitude may help foster the circular relationship between autonomy and collaboration proposed by Clement and Vandenberghe (2000) wherein both positively reinforce each other.

Second, the type of collaboration one is looking at may also help explain the complex relationship with teacher autonomy. While superficial types of collaboration can perfectly match with a preference for individualised autonomy (Lortie, 1975), interdependence and disagreements resulting from deep-level collaboration may prove to be more challenging (Moolenaar, 2010). Hence, while some types of (superficial) collaboration are perfectly compatible with a focus on individualised autonomy and a reactive attitude, deep-level collaboration requires interdependence among teachers and may challenge teachers' definition of autonomy. 


\section{Present Study: Aims and Research Questions}

The aim of this study was to investigate how teachers' understanding of autonomy (i.e., attitude) can help understand the relationship between teacher autonomy and collaboration. Regarding autonomy, the framework proposed by Author(s) (2017a), distinguishing between classroom autonomy (didactical-pedagogical and curricular) and attitude towards autonomy as described in the theoretical framework, was followed. With regard to collaboration the framework of collaborative activities of de Vries et al. (2013) was used with the addition of constructive conflict, resulting in three collaborative activities: exchange activities, professional collaboration, and constructive conflict. In Flanders (Belgium), secondary schools are mostly structurally organised in a way to foster teacher collaboration in different groups or departments, such as subject groups. These are structural units within schools gathering teachers who teach the same (or related) subject(s) and who are expected to collaborate concerning subject-related matters (e.g., curriculum, student evaluation). It was opted to focus on collaboration in subject groups because they are meaningful collaborative units in all schools that are organised to collaborate on core teaching issues in line with the domains of autonomy described earlier.

This results in the following research questions:

RQ1. How are classroom autonomy (didactical-pedagogical and curricular), teachers' autonomy attitude (individualistic/reactive or collaborative/reflective), and different collaborative activities related?

$R Q 2$. How do these relationships manifest across individuals: Do teachers with different autonomy interpretations report different degrees of collaboration?

$R Q 3$. How can teachers' conceptions and appreciations of autonomy and collaboration in their classroom practice help explain these relationships?

$R Q 4$. What other factors help explain the relationship between teachers' sense of autonomy and their willingness to collaborate?

Study Design and Method 
To gain in-depth understanding of these relationships, different methods were combined. The design can be described as a fully mixed sequential explanatory design where qualitative data are used to contextualise and further explain quantitative findings (Leech \& Onwuegbuzie, 2009; Ivankova, Creswell, \& Stick, 2006). Questionnaire data were collected to quantitatively tackle the first two research questions. Given the importance of cross-validating research findings, the analyses were performed on two independent samples $\left(N_{l}=1610 ; N_{2}=1408\right)$. In a subsample of teachers $(n=17)$, interviews were conducted. Qualitative analyses verify the results of the quantitative analyses and provide possible (alternative) explanations.

\section{Instruments}

Quantitative: Questionnaire. The questionnaire of Author(s) (2017a) was used to assess teachers' autonomy and attitude. It consists of three scales: didactical-pedagogical autonomy (7 items), curricular autonomy (4 items), and collaborative attitude (10 items). The latter scale aims to be an indicator of teachers' autonomy attitude as the main distinction between a reactive and reflective attitude includes teachers' openness towards external influences: Whereas a reactive attitude focuses on individualism and independence, a reflective attitude includes openness towards collaboration and external influences. Autonomy items (e.g., "I am free to select the teaching methods and strategies that seem most appropriate to me") were answered on a 6-point Likert scale ranging from completely disagree (1) to completely agree (6). For the attitude scale, teachers had to take a position in between two statements, one referring to a preference for working individually and independently (1) and one indicating a preference for and valuing of collaborative work (6) (e.g., "I prefer to select teaching methods individually, without colleagues. - With respect to the selection of teaching methods, I find it useful and desirable to discuss and collaborate with colleagues"). A high score on this scale refers to a collaborative attitude valuing collaboration and consultation with colleagues; a low score indicates an individualistic attitude focused on independence.

To assess collaborative activities, an adapted version of the collaboration component of the questionnaire of de Vries et al. (2013) was used. The latter consists of 16 items and contains exchange activities (e.g., sharing ideas, instructional materials) and professional collaboration (e.g., joint 
preparation of teaching and evaluation materials, discussing student performance results). One item was added to emphasise the reciprocal nature of exchange activities (sharing materials was added in line with using materials of others) and three items were added to capture constructive conflict. The items were slightly adapted to focus on collaboration with subject group colleagues. Items were answered on a 7-point Likert scale ranging from never (1) to always (7). Example items include "I share new teaching ideas with colleagues in the subject group" (exchange activities), "I construct (digital) teaching materials with colleagues in my subject group" (professional collaboration) and "I openly discuss professional disagreements with colleagues in this subject group" (constructive conflict).

After omitting three items in the exchange activities scale due to high covariances, the results of the CFA for sample 1 indicated an appropriate fit of the scales with our data $\chi^{2} / d f=4.63, \mathrm{CFI}=.92$, $\mathrm{TLI}=.92, \mathrm{RMSEA}=.047$ [90\% CI $[.046 ; .049]]$, SRMR=.042), fit indices meeting the generally accepted norms for CFA (Brown \& Cudeck, 1993; Hu \& Bentler, 1999). The fit of this structure was confirmed in sample $2\left(\chi^{2} / d f=4.49, \mathrm{CFI}=.92, \mathrm{TLI}=.91, \mathrm{RMSEA}=.050 \quad[90 \%\right.$ CI $[.048 ; .052]]$, SRMR=.042). Cronbach's alpha values of all scales indicated sufficient reliability (Table 3).

Qualitative: Interviews. For the qualitative part, semi-structured interviews were used. One pilot interview was performed to check the clarity of the questions. Based upon this interview, questions were added to the guideline to more closely investigate collaboration (e.g., negative sides of collaboration). The final guideline consisted of questions on teachers' perceived autonomy, collaboration, the experienced relationship between autonomy and collaboration, and the evolution thereof throughout their career. Before the interview started, all respondents signed informed consent forms. The interviews lasted about 20 to 55 minutes (mean of about 40 minutes). To improve the authenticity and validity of the data, participants were asked to check whether their transcripts correctly captured their responses.

\section{Samples}

Quantitative data were collected from two independent samples. The first sample consists of 1610 teachers from 37 secondary schools and 374 different subject groups and was collected in 
November-December 2015. The second sample consists of 1408 teachers from 22 other schools and 376 different subject groups and was collected in March 2016. Demographic characteristics can be found in Table 1.

Table 1

Demographic Characteristics Survey Respondents

\begin{tabular}{|c|c|c|}
\hline & Sample $1(\mathrm{~N}=1610)$ & Sample $2(\mathrm{~N}=1408)$ \\
\hline \multicolumn{3}{|l|}{ Gender } \\
\hline Female (\%) & $1005(62.42 \%)$ & $1023(72.65 \%)$ \\
\hline Male (\%) & $605(37.57 \%)$ & $385(27.34 \%)$ \\
\hline \multicolumn{3}{|l|}{ Age } \\
\hline Mean & 41.36 & 40.80 \\
\hline Min - Max & $21-62$ & $22-63$ \\
\hline$S D$ & 10.43 & 10.29 \\
\hline \multicolumn{3}{|l|}{ Teaching experience } \\
\hline Mean & 16.50 & 15.27 \\
\hline Min - Max & $0-46$ & $0-41$ \\
\hline$S D$ & 10.52 & 10.29 \\
\hline \multicolumn{3}{|l|}{ Type of appointment } \\
\hline Ad interim (\%) & $139(8.63 \%)$ & $114(8.10 \%)$ \\
\hline Permanent appointment (\%) & $1298(80.62 \%)$ & $1100(78.13 \%)$ \\
\hline
\end{tabular}

For the qualitative part, purposive sampling was used to collect a diverse sample and include different perspectives to explain and contextualise quantitative findings. At the end of the questionnaire, teachers in sample 1 were asked to indicate whether they were willing to participate in an interview on their perceptions of autonomy. From the sample of teachers who indicated to be prepared to do this $(n=480)$, extreme cases regarding autonomy and attitude towards autonomy were selected to get a diverse sample. This was done in two steps. First, teachers were ordered based upon their attitude scores and the teachers with the most collaborative attitude (a score above 5.5 on a 6 point scale) and most individualistic attitude (a score of 3 or below) were selected. Next, this selection of teachers was ordered based upon reported autonomy and again the highest and lowest scoring respondents were selected. In this way, teachers with both combinations of high and low perceived autonomy and collaborative or individualistic attitude were present in the selection. These teachers were contacted via e-mail and a sample of 17 teachers participated in the interviews, including eigth female and nine male teachers with ages ranging from 25 to $57(M=41.35, S D=9.52)$. This sample 
includes more teachers with a high collaborative attitude $(11 ; 64.71 \%)$, which corresponds with the fact that the full quantitative sample includes more teachers in the category scoring high on collaborative attitude $(n=852 ; 60.51 \%)$. Table 2 presents demographic characteristics of this subsample.

Table 2

Demographic Characteristics Interview Respondents

\begin{tabular}{|c|c|c|c|c|c|}
\hline & Gender & $\begin{array}{l}\text { Teaching } \\
\text { experience }\end{array}$ & Subject(s) & Attitude & $\begin{array}{l}\text { School size } \\
\text { (\# teachers) }\end{array}$ \\
\hline Respondent 1 & Female & $>20$ years & Religion & Individualistic & $>100$ \\
\hline Respondent 2 & Female & $>20$ years & Languages & Individualistic & $>100$ \\
\hline Respondent 3 & Male & $>20$ years & Religion, History & Individualistic & $<50$ \\
\hline Respondent 4 & Male & $10-20$ years & $\begin{array}{l}\text { Practical subjects } \\
\text { (technical/vocational } \\
\text { education) }\end{array}$ & Individualistic & $50-100$ \\
\hline Respondent 5 & Male & $10-20$ years & Religion & Individualistic & $50-100$ \\
\hline Respondent 6 & Male & $>20$ years & Languages & Individualistic & $50-100$ \\
\hline Respondent 7 & Female & $>20$ years & Mathematics & Collaborative & $>100$ \\
\hline Respondent 8 & Female & $5-10$ years & Languages & Collaborative & $<50$ \\
\hline Respondent 9 & Female & $10-20$ years & Sciences & Collaborative & $>100$ \\
\hline Respondent 10 & Female & $>20$ years & Mathematics & Collaborative & $>100$ \\
\hline Respondent 11 & Male & $<5$ years & $\begin{array}{l}\text { Practical subjects } \\
\text { (technical/vocational } \\
\text { education) }\end{array}$ & Collaborative & $>100$ \\
\hline Respondent 12 & Male & $>20$ years & Mathematics & Collaborative & $>100$ \\
\hline
\end{tabular}




$\begin{array}{llllll}\text { Respondent } 13 & \text { Female } & 10-20 \text { years } & \text { Religion, History } & \text { Collaborative } & 50-100 \\ \text { Respondent } 14 & \text { Male } & 10-20 \text { years } & \text { Sciences } & \text { Collaborative } & <50 \\ \text { Respondent } 15 & \text { Male } & >20 \text { years } & \text { Languages } & \text { Collaborative } & >100 \\ \text { Respondent } 16 & \text { Female } & 10-20 \text { years } & \text { Languages } & \text { Collaborative } & >100 \\ \text { Respondent } 17 & \text { Male } & <5 \text { years } & \text { Physical education } & \text { Collaborative } & 50-100\end{array}$

\section{Analyses}

Quantitative analyses. Variable-centred and person-centred analyses were combined. While variable-centred approaches indicate how variables relate to one another, person-centred analyses demonstrate how these variables are interrelated and manifested within different latent profiles of teachers. This adds to previous theorising on the topic by answering questions as: Which autonomy profiles can be distinguished across teachers and which are most conducive to collaboration?

First, correlations among the variables were assessed by means of a multilevel structural equation modelling (SEM) approach (Maximum Likelihood estimation with robust standard errors). Given that the scales assessing collaborative activities refer to the subject group and the data have a nested structure (teachers nested in subject groups and schools), ICC values were calculated to quantify the degree of between-level variance on the subject group and school-level (Appendix A). School-level variance appeared to be minimal and most of the variance was situated at the individuallevel. There is some degree of subject group-level variance (most prominent for curricular autonomy and professional collaboration). Given that the research questions are situated at the level of individual teachers, analyses were performed at the within-level, defining a measurement model and the relationships at this level. However, analyses were performed taking subject group-level variance into account. All items were allowed to vary at the between-level, in this way decomposing within- and between-level variance to make sure that variation due to subject group membership was excluded at the individual-level. 
Next, latent profiles of teachers were identified based upon perceived didactical-pedagogical autonomy, curricular autonomy, and collaborative attitude. A factor mixture modelling (FMM) approach combines the classic latent profile model and a common factor model (Lubke \& Muthén, 2005). The FMM used here is made up of two parts: (1) a measurement (factor) model that is invariant across all identified profiles and (2) a K-component normal mixture model for the underlying factors (i.e., didactical-pedagogical autonomy, curricular autonomy, collaborative attitude) (Wall, Guo, \& Amemiy, 2012). A parametric multilevel approach consisting of two steps was used (Henry \& Muthén, 2010). First, traditional FMM was used to determine the number of individual-level latent profiles. Next, random effects were added as individual-level profile intercepts were allowed to vary across subject groups. This allows the probability of being a member of a certain individual-level profile to vary across subject groups (Henry \& Muthén, 2010). A common factor was used to model the random means and related covariances (Henry \& Muthén, 2010). Models with one to four different profiles were compared based upon their Log-likelihood, sample size-adjusted Bayesian Information Criterion (BIC), Vuong-Lo-Mendell-Rubin likelihood ratio test (VLMR-LRT), the adjusted LoMendell-Rubin likelihood ratio test (Adjusted LRT), and conceptual interpretability of the solution. Finally, the teacher profiles were compared with regard to their reported levels of collaboration. ANOVA analyses were used to compare the means of these profiles. For the multilevel correlations and FMM analyses Mplus version 7 was used and for the ANOVA analyses SPSS version 24.

Interview analyses. Interviews were transcribed and encoded by means of qualitative content analysis. Data coding was performed in an iterative process as suggested by Roller and Lavrakas (2015). In a first step of data familiarisation, the transcripts were read and reread to absorb the content. Second, the unit of analyses was determined as relevant meaningful fragments of text data that contributed to answering the proposed research questions (i.e., are related to the topics of autonomy and collaboration). These fragments ranged from single sentences to an entire response to a particular question and are focused on one specific aspect (e.g., exchange activities) that can be coded in the next step. Third, codes were developed through a combination of a deductive and inductive approach. A priori deductive codes were derived from the theoretical framework. Based upon an inductive approach, reading into the data, new codes were identified and a priori codes were refined. The coding 
of the data was done iteratively. After going through the data and coding the data in a first iteration, the coding scheme was refined and structured. Next, a second iteration of axial coding was performed in order to reassess and refine the coding. After encoding the data, the codes were assigned to categories and a hierarchical tree structure was built using NVivo 11. The tree structure was built around three main codes: autonomy, collaboration, and the relationship between both (Appendix B).

\section{Results}

\section{Perceived Autonomy and Collaboration}

Descriptive statistics are provided in Table 3. The level of curricular autonomy appears to be lower than the degree of didactical-pedagogical autonomy. In the interviews, all teachers argued the latter to be the most important domain of autonomy. Teaching style and preferences are described by seven respondents as intrinsically related to who they are as a person, for example Respondent 13 argued that 'You can't disconnect how you teach from who you are as a person, that's for sure. You really can't, because you are not playing a role as a teacher, you just are who you are." Moreover, four teachers argued this to be related to being able to appropriately address students' needs, for example:

Students most like a teacher who shows himself as he is. And thus who really speaks from his passion and those are the teachers who make a lasting impression. And therefore you shouldn't force teachers into a straightjacket because that does not work after all. (Respondent 6)

Four teachers argued that didactical-pedagogical autonomy can counterbalance restricted levels of curricular autonomy. The latter is restricted by curricula that are imposed by the government and determine the boundaries within which teachers can act autonomously in their classroom with regard to didactical-pedagogical aspects: "With respect to the curriculum and so forth, that's all fixed so that's about the only... Yes, you are of course required to follow that, but you can teach that in different way (Respondent 11)."

Table 3 
Descriptive Statistics

\begin{tabular}{llllll}
\hline Scale & Sample & $N$ & $M$ & SD & Cronbach's $\alpha$ \\
\hline Didactical-pedagogical & Sample 1 & 1610 & 4.93 & .60 & .81 \\
autonomy & Sample 2 & 1408 & 4.88 & .64 & .83 \\
Curricular autonomy & Sample 1 & 1610 & 4.12 & .86 & .73 \\
& Sample 2 & 1408 & 4.20 & .87 & .77 \\
Collaborative attitude & Sample 1 & 1610 & 4.40 & 1.13 & .94 \\
& Sample 2 & 1408 & 4.32 & 1.17 & .94 \\
Exchange activities & Sample 1 & 1604 & 4.57 & 1.23 & .91 \\
\multirow{5}{*}{ Professional collaboration } & Sample 2 & 1399 & 4.40 & 1.22 & .92 \\
& Sample 1 & 1604 & 3.23 & 1.33 & .88 \\
Constructive conflict & Sample 2 & 1399 & 3.01 & 1.24 & .87 \\
& Sample 1 & 1604 & 4.46 & 1.64 & .93 \\
& Sample 2 & 1399 & 4.34 & 1.62 & .94 \\
\hline
\end{tabular}

Regarding collaborative activities, less professional collaboration is reported compared to exchange activities and constructive conflict. When looking more deeply into the types of collaboration reported in the interviews, all teachers focused on content-related aspects and described collaboration regarding these aspects as self-evident. As such, exchange activities mostly include making agreements on evaluation (e.g., number of tests, content of exams) and exchanging course materials rather than discussing teaching methods/strategies. Three respondents explicitly stated this, for example: "What I'd rather not discuss, is the way in which I teach the course material. That is different for everyone. And I have my style and that is different from that of all others (Respondent 6).” Professional collaboration was mostly focused on collectively making exams (eight respondents) or developing teaching materials (reported by six teachers), although the latter was argued to be less frequent. In the interviews, five teachers explicitly mentioned that they could openly share their opinion and discuss disagreements. They stated for example that "when something is brought up that I do not agree with, I just say it" and "we discuss each others' opinions and someone has this opinion and someone else has that opinion. Yes, it's a lively team, everyone voices his opinion". However, the interviews also nuance the relatively high quantitative scores on constructive conflict, as voicing disagreements does not always lead to deep-level discussions and constructive negotiation. One of the respondents referred to the need to compromise in order to find consensus - focused on finding agreement or giving in rather than exploring and integrating different viewpoints - and two others 
referred to the freedom to still do their own thing within their classes, which makes further discussions less important.

Furthermore, the interview analyses indicated that the subject group is a meaningful reference point for collaboration. Twelve of the interviewed teachers automatically referred to the subject group, or more specifically to parallel colleagues (teaching the same subject in the same grade) (ten respondents), when asked about collaboration.

\section{The Relationship Between Autonomy and Collaboration}

Exploring the relationship. Table 4 demonstrates that in both samples, collaborative attitude was consistently related to the different collaborative activities. Didactical-pedagogical autonomy was found to be positively related to reported exchange activities and constructive conflict, but not professional collaboration. Similarly, in the interviews teachers mostly demonstrated openness to discuss certain didactical-pedagogical matters but also tend to be protective of their individuality in this domain in the sense that they prefer not to be influenced by others and tend to be cautious towards deep-level collaborative activities. Most teachers argue to regularly exchange teaching materials such as tests, assignments, and exams but this tends to be restricted to the act of exchanging rather than deep-level discussions of underlying conceptions and beliefs about teaching. Moreover, although most teachers (13) state that they are open to share their classroom practice (e.g., co-teaching, collaborating on teaching methods), almost all respondents indicated that this does not often happen in practice. Four teachers explicitly stated not to want to collaborate on teaching methods themselves, for example Respondent 9 argued that "basically I think everything can be discussed, but there are certain things, such as how you explain or teach certain things or whatever, in which you need to respect each other's freedom". Others (six teachers) refer to their colleagues as being less open to collaborate on this topic and being resistant because they are not used to it, are insecure, or fear being judged or criticised.

Table 4

Correlations

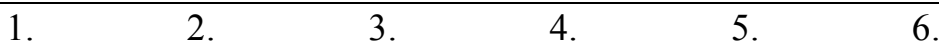


Sample 1

1. Exchange activities

2. Professional $.742 * * *$

collaboration

3. Constructive conflict $\quad .558^{* * *} \quad .449^{* * *}$

4. Didactical-pedagogical $\quad .158^{* * *} \quad .020 \quad .206^{* * *}$ autonomy
5. Curricular autonomy
$.147 * * *$
$.115^{* * *}$
$.183^{* * *} \quad .638^{* * *}$
6. Collaborative attitude
$.237 * *$
$.213 * * * \quad .111^{* * *}$
$.127 * * * \quad-.018$
7. Teaching experience
$\begin{array}{lll}-.100 * * * & -.138 * * * & .011\end{array}$
$-.079 * * \quad-.046$

Sample 2

1. Exchange activities

2. Professional

$.717 * * *$

collaboration

3. Constructive conflict

$.589 * * * \quad .472 * * *$

4. Didactical-pedagogical

$.067 *$

$-.027$

$.162 * * *$ autonomy

5. Curricular autonomy

.054

.045

$.086^{* *}$

$.750 * * *$

6. Collaborative attitude

$.310^{* * *}$

$.307 * * *$

$.114 * * *$

.004

$-.009$

7. Teaching experience

$-.090^{* *}$

$-.081 * * \quad .013$

$-.048$

$-.066^{*} \quad-.153 * * *$

Regarding curricular autonomy only the relationship with constructive conflict was found to be consistent across both samples. These mixed results regarding curricular autonomy may be related to the fact that the latter is perceived to be mostly influenced by curricula imposed by governmental institutions rather than influences at the level of teachers' colleagues and school. However, these curricula are also subject-specific and can thus also be related to subject group collaboration, some curricula leaving more room for autonomy and collaborative activities. Respondents teaching "exact" subjects (mathematics, chemistry) indicated their curricula to be more restrictive compared to for example languages or religion. As stated by one of the respondents: "Moreover, our curriculum is much like a checklist, very theoretical like 'this and this and this' has to be covered. And there are simply not that many different ways to do that (Respondent 9)." 
The qualitative analyses demonstrated that the relationship between autonomy and collaboration is also influenced by how teachers understand collaboration. When talking about collaboration, teachers often referred to making agreements and having to do things the same way as colleagues (mostly regarding course content and materials, student evaluation). For example, seven respondents argued that having parallel colleagues impacts their autonomy because they "have to agree on what they are going to do". Hence, teachers tend to relate collaboration to assimilating or equalising what they are doing with what their colleagues are doing. Given that teachers feel that didactical-pedagogical aspects of teaching are strongly personal, this helps explain why teachers tend to be more apprehensive towards collaboration in this area. Collaboration as assimilation was also mentioned by one teacher in the context of the juridification of education: "because of the juridification of education - we did not yet have too many issues here - colleagues are starting to collaborate more and make more agreements, also in order not to be on their own in disputes (Respondent 6)." However, having to use the same exams as parallel colleagues was also mentioned by two teachers as being stressful and limiting their freedom. It puts a strain on collaboration as the latter then sprouts from external push factors rather than an internal need or desire.

Furthermore, teaching experience was negatively related to reported exchange activities, professional collaboration, and collaborative attitude. In the interviews, five respondents argued that younger teachers are more open to collaboration while older teachers tend to prefer solitary work in their classroom. Similarly, younger respondents tended to experience a balance between autonomy and collaboration, for example:

Autonomy and collaboration need to be united because when you collaborate, your teaching becomes better. So actually, when you're on your own, working autonomously gets harder. They go hand in hand: If you want to work well autonomously, you have to collaborate as well" (Respondent 17).

The highly experienced respondents argued that they have built up enough expertise to work independently: "After all those years, you have more expertise and, so to speak, people should not tell me anymore how I am supposed to teach. Now I'm not afraid to go my own way" (Respondent 15). They seem to feel more confident and value autonomy as an appreciation and recognition of their 
expertise. Teachers' (perceived) role in collaboration also seems to shift from asking support to providing support to younger colleagues, for example: "I used to mostly listen during collaborative work, maybe now I have become more of a counsellor" (Respondent 1).

Autonomy profiles. In the first step, FMM ignoring the nesting of teachers in subject groups was performed to identify the number of individual-level profiles. Models identifying one to four profiles were tested. Adding more profiles reduced the log-likelihood and BIC values. When comparing the model with three profiles with the two-profile model, a conceptually meaningful and distinguishable profile was added. The results of the VLM-LRT (both samples: $p<.001$ ) and adjusted LRT (both samples: $p<.001$ ) supported the three-profile solution. The entropy values of .772 (sample 1) and .804 (sample 2) indicated an acceptable classification quality of this model.

Next, the means of this individual-level three-profile solution were allowed to vary across subject groups. In order to verify whether this solution was still most appropriate, the models with two and four latent profiles were also tested using the multilevel FMM approach. Based upon comparison of log-likelihood, adjusted BIC values, conceptual meaningfulness of the identified profiles, and VLMR-LRT and adjusted LRT tests, the three-profile solution was selected (see Appendix C for detailed results). Entropy values of this model are .755 (sample 1) and .794 (sample 2).

Table 5 presents the results of this model. The first - largest - profile had high levels of both autonomy and collaborative attitude (autonomous collaborative profile, cf. reflective attitude). The second profile consisted of teachers with a high degree of autonomy and a more individualistic attitude (autonomous individualistic profile, cf. reactive attitude). Finally, the third - smallest - profile included teachers reporting high levels of didactical-pedagogical autonomy and collaborative attitude but lower curricular autonomy (low curricular autonomy collaborative profile, cf. reflective attitude). Hence, the difference between the profiles was based upon curricular autonomy and collaborative attitude, didactical-pedagogical autonomy was high in all profiles.

Table 5

Results Multilevel FMM With Three Profiles

$\begin{array}{ccccc}\mathrm{N} & \text { Average latent } & \text { Didactical- } & \text { Curricular } & \text { Collaborative } \\ (\%) & \text { class } & \text { pedagogical } & \text { autonomy } & \text { attitude }\end{array}$




\begin{tabular}{cccccc}
\hline \multicolumn{5}{c}{ probabilities } & autonomy \\
Pample 1 & 1150 & .906 & $5.282(.033)$ & $4.414(.060)$ & $4.513(.055)$ \\
Profile 1 & $(71.43 \%)$ & & & & \\
Profile 2 & 311 & .856 & $5.375(.054)$ & $4.595(.092)$ & $2.555(.086)$ \\
& $(19.32 \%)$ & & & & \\
Profile 3 & 149 & .839 & $5.426(.062)$ & $2.794(.158)$ & $4.435(.106)$ \\
& $(9.25 \%)$ & & & & \\
Sample 2 & 976 & .924 & $5.222(.031)$ & $4.533(.052)$ & $4.792(.053)$ \\
Profile 1 & $(69.32 \%)$ & & & & \\
Profile 2 & 298 & .889 & $5.342(.055)$ & $4.639(.077)$ & $2.417(.075)$ \\
& $(21.16 \%)$ & & & & \\
Profile 3 & 134 & .864 & $5.284(.051)$ & $2.969(.103)$ & $4.400(.125)$ \\
& $(9.52 \%)$ & & & & \\
\hline
\end{tabular}

When asked about what autonomy means to them in the interviews, some teachers refer to a predominantly reactive understanding (focused on independence) and others focus on reflective elements (self-government based upon own values and vision), but most respondents (15) refer to both reflective and reactive aspects. Most teachers (9) refer to autonomy as freedom within certain limits (e.g., curriculum, agreements made with colleagues). A few teachers initially equate autonomy to independence, for example "autonomy means working independently, without direct influence of others" (Respondent 12), "being the boss in your own classroom" (Respondent 2), or "having to take little account of others or of limitations imposed by the school management, curricula, school inspection, etc." (Respondent 15). However, later on they indicate that collaboration is key and that autonomy should be combined with collaborative work. Almost all respondents (14) indicated collaboration today to be a must in education.

Latent profile comparisons. Next, it was assessed whether different degrees of collaboration were reported by the different profiles. Significant Levene statistics indicated that the assumption of equal variances was violated for some of the collaborative activities. Following this, Welch's $F$-test for comparing means was used. Results (Table 6) demonstrated that only for exchange activities and professional collaboration significant differences were found. Furthermore, the impact of teaching experience was assessed and Welch's $F$-test demonstrated significant differences in experience across the profiles. However, effect sizes $\left(\eta^{2}\right)$ indicate that overall small effects were found. 
Table 6

Results ANOVA Latent Profiles (Welch's F-Test)

\begin{tabular}{lllll}
\hline & $\mathrm{df}$ & $F$ & $p$ & $\eta^{2}$ \\
\hline Sample 1 & & 12.52 & $<.001$ & .017 \\
$\begin{array}{l}\text { Exchange } \\
\text { activities }\end{array}$ & 2 & 13.82 & $<.001$ & .017 \\
$\begin{array}{l}\text { Professional } \\
\text { collaboration }\end{array}$ & 2 & .163 & .849 & .000 \\
$\begin{array}{l}\text { Constructive } \\
\text { conflict }\end{array}$ & 2 & 5.53 & $<.01$ & .007 \\
$\begin{array}{l}\text { Teaching } \\
\text { experience }\end{array}$ & 2 & 18.39 & $<.001$ & .029 \\
$\begin{array}{l}\text { Sample } 2 \\
\text { Exchange }\end{array}$ & 2 & 23.67 & $<.001$ & .032 \\
$\begin{array}{l}\text { activities } \\
\text { Professional } \\
\text { collaboration }\end{array}$ & 2 & .943 & .390 & .001 \\
$\begin{array}{l}\text { Constructive } \\
\text { conflict }\end{array}$ & 2 & 15.95 & $<.001$ & .023 \\
$\begin{array}{l}\text { Teaching } \\
\text { experience }\end{array}$ & 2 & & & \\
\hline
\end{tabular}

Post hoc tests were performed to investigate how the identified profiles differed. Given that equality of variances among the profiles could not be assumed and the profiles had different numbers of members, a Games-Howell test was used. Results in Table 7 indicate that regarding exchange activities, only between the autonomous collaborative profile and the autonomous individualistic profile a significant difference was found consistently in both samples, the first having a higher mean score. With regard to professional collaboration, the autonomous collaborative profile had a significantly higher mean score compared to the profiles with an individualistic attitude and with low curricular autonomy. Finally, teachers in the autonomous individualistic profile overall had more years of teaching experience compared to teachers in the autonomous collaborative profile. 
Table 7

Descriptive Statistics and Games-Howell Post Hoc Test

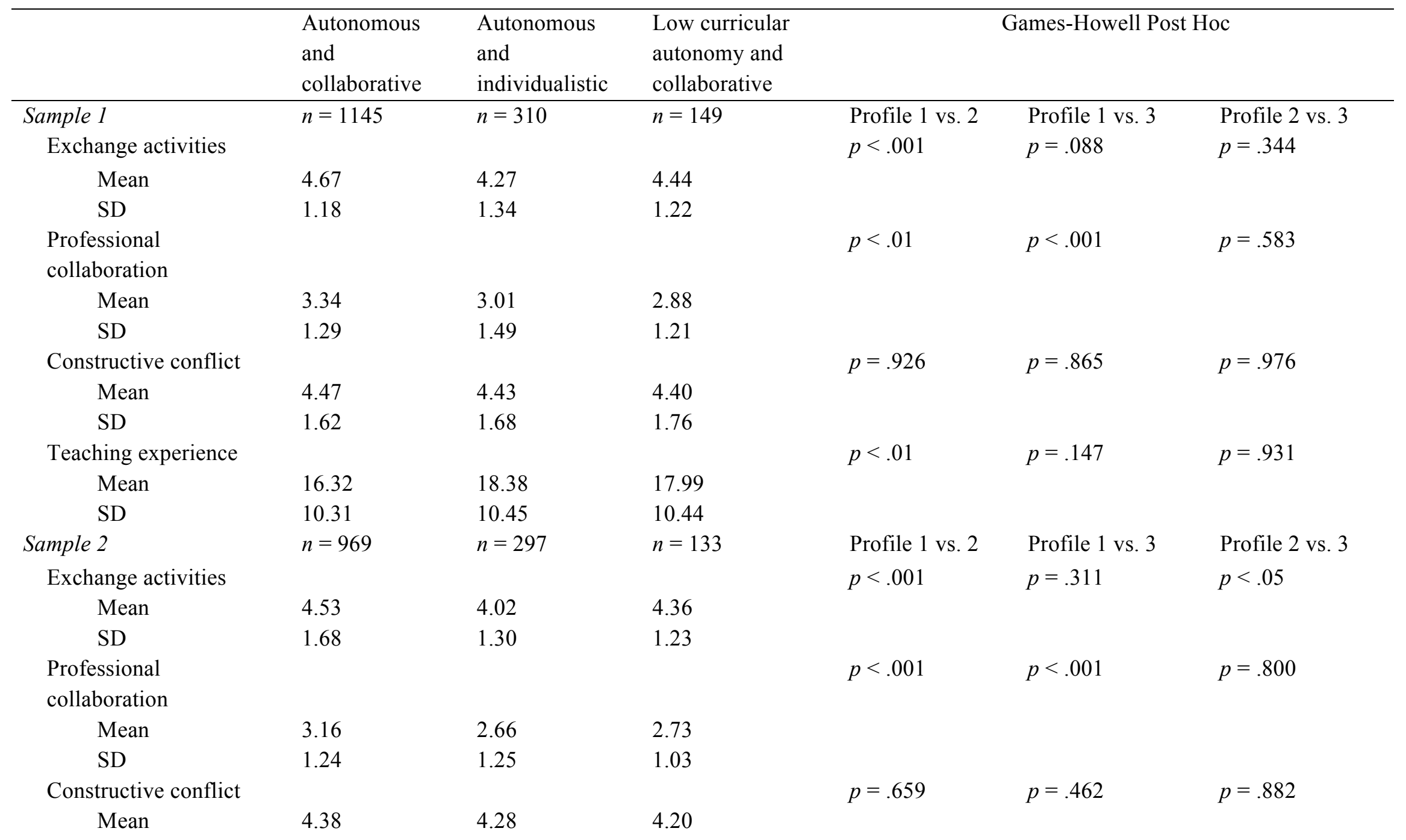


SD

Teaching experience

Mean

SD
1.59

14.26

10.02
1.70

18

10.54
1.64

$p<.001$

$p<.05$

$p=.433$

10.30 
Towards a deeper level understanding. Results of the interview analyses mostly support quantitative results but also help explain limited effect sizes and provide a more nuanced understanding. As such, the identified latent profiles all demonstrated high levels of didacticalpedagogical autonomy. However, when talking about tensions between autonomy and collaboration, teachers referred to didactical-pedagogical aspects such as the choice of textbooks, managing time and planning; or even more sensitive topics seem to be teaching methods and classroom management. Teachers' attitude thus seems to differ depending on the domain and specific aspect of collaboration. While a more reflective attitude comes forward regarding curricular or content-related topics (textbooks and course materials, student evaluation, planning), a more reactive attitude towards autonomy tends to be demonstrated regarding teaching methods or style, and classroom management. Moreover, for some teachers focusing on a reactive understanding of autonomy, their autonomy and collaboration become more compatible by imposing limits to collaborative activities that still guarantee their individuality. For example, one teacher argued that "I think that they [i.e., autonomy and collaboration] can go together because I set my own limits. Yes, we have the same tests but aside from that I make my own choices. And even though we have the same tests, I am still responsible for the final decision" (Respondent 2).

Furthermore, there are other factors constraining collaboration that are beyond the power of teachers themselves. Respondents mentioned that having no (or little) parallel colleagues strongly fosters their autonomy (seven respondents) but at the same time this can limit teachers' opportunities to collaborate (mentioned by four teachers): "It has advantages and disadvantages. I am on my island sometimes, but no one bothers me on my island. But on the other hand, I can't call a helpline (Respondent 15)". Another frequently occurring issue includes lack of (common) time for collaboration (mentioned by eight respondents).

Moreover, ten of the teachers reported strong differences between formal top-down and informal spontaneous collaboration. As stated by one of the respondents: "In this school, those subject group meetings are not really useful to us as teachers because they mainly consist of tasks that are imposed by the school and some of them are unnecessary (Respondent 10)." Compulsory top-down collaboration was perceived more negatively and less relevant, often described in relation to getting 
proof of their collaborative work on paper and putting more strains on teachers' autonomy. Spontaneous collaboration on teachers' own terms was perceived to be more positively related to autonomy. It was often experienced as more useful and motivating because it is more directly linked to current issues experienced in classroom practice. However, while too much top-down interference (e.g., imposing meeting times or topics to be discussed) is negatively received by teachers, too little (practical) support by the school principal was also put forward by one respondent as a factor strongly hindering collaborative work. Almost all respondents argued that the school principal stimulates collaboration, but this should also be balanced with sufficient support for teachers' autonomy, three respondents argued this to be a sign of trust in their professionalism and expertise.

Another factor influencing teacher collaboration reported by nine respondents includes that there needs to be a feeling of equality and a personal fit, they need to feel a connection with their collaborative partner. In this regard, teachers refer to social aspects of liking each other (e.g., "If you don't really 'click' with someone, so if it doesn't work well on a personal level, then it will also not work on a professional level (Respondent 14)”) as well as having similar professional and pedagogical beliefs (e.g., 'I can imagine that if that is with someone you don't 'click' with, who emphasises different things, that can be difficult sometimes (Respondent 7)"). A sense of social cohesion and collegiality is perceived to foster the balance between autonomy and collaboration. Teachers' collaborative attitude thus partly depends on whom it is they are supposed to collaborate with:

I think that [i.e., the relationship between autonomy and collaboration] to a large extent depends on whether you get along or not. If you have more or less the same attitude, that will make a large difference, then you don't have the feeling that [collaboration] limits your autonomy (Respondent 7).

\section{Conclusion and Discussion}

This study aimed to gain insight into the relationship between teacher autonomy and collaboration, which are both perceived as important working conditions by teachers.

\section{Exploring the Relationship Between Autonomy, Attitude, and Collaboration}


The first research question focused on exploring how classroom autonomy, teachers' autonomy attitude (reactive/individualistic or reflective/collaborative) and different collaborative activities are related. The results demonstrated that autonomy can be combined with an individualistic or collaborative attitude. Autonomy in itself demonstrates ambiguous relationships with collaboration, consistent positive correlations across both samples were only found for constructive conflict. However, teachers' attitude is consistently related to collaborative activities. Hence, the distinction between a reactive and a reflective autonomy attitude provides a first step in the improved understanding of the relationship between autonomy and collaboration.

\section{A Person-Centred Perspective: Autonomy Profiles}

Second, we assessed how these relationships manifest across individuals and whether teachers with different autonomy interpretations report different degrees of collaboration. Three latent teacher profiles were identified based upon their perceived autonomy and attitude: Autonomous and collaborative (ca. $70 \%$ of the respondents), autonomous and individualistic (ca. 20\%), and low curricular autonomy and collaborative profile (ca. 10\%). Hence, teachers perceived high levels of autonomy - especially didactical-pedagogical - and endorsed a more reflective attitude, valuing collaboration. When comparing reported collaboration in the profiles, significant but small differences were found for exchange activities and professional collaboration, but not constructive conflict. Hence, while significant correlations were found between autonomy and collaborative attitude on the one hand and constructive conflict on the other hand, no effects were found for constructive conflict when comparing profiles. This demonstrates the value of including a person-centred approach, looking at how variables and processes manifest and interact across individuals. The results for exchange activities - a significant difference was found between the autonomous collaborative and autonomous individualistic profile - indicate that especially in the case of high levels of autonomy, a collaborative attitude influences reported collaborative activities. When looking at professional collaboration, both collaborative attitude and curricular autonomy appeared to be influential. Very strict curricula leave less room for teachers' creativity and freedom while a certain amount of openness may foster and support collective teacher creativity in tackling educational challenges both collaboratively and 
individually. However, small effect sizes nuance the implications of these findings. These small effects may partially be explained by the fact that there is still substantial variance within each profile.

\section{Teachers' Understanding of Autonomy and Collaboration in Practice}

The results for research question 3 - how teachers' understanding of autonomy and collaboration in their classroom practice can help explain these relationships - used the qualitative data to explain our quantitative findings. In line with the quantitative results, teachers mostly referred to freedom within certain boundaries in the interviews (e.g., curricula, agreements made in subject groups), similar to the reflective description of autonomy proposed by Wermke and Höstfält (2014) who described autonomy as teachers' action range to react to the dilemma between teachers' work in the classroom and depending on organisational structures (such as the school and curriculum provided by state governance). However, teachers also argued that having parallel colleagues can limit autonomy, demonstrating a reactive attitude excluding interference from others. Most teachers combined reflective and reactive elements when talking about autonomy. The results also demonstrated that this seems to be related to specific domains. The possibly tensed relationship between autonomy and collaboration is more clearly manifested in didactical-pedagogical autonomy. Certain aspects thereof (teaching methods, managing student behaviour) are experienced as very personal, creating a more challenging relationship to collaboration. Teachers may feel insecure or fear being judged or criticised and discussing these aspects exposes teachers' underlying beliefs about teaching, which may increase the risk of conflicts or disagreements among teachers (Johnson, 2003; Kelchtermans, 2006). Curricular autonomy is mostly influenced by institutions external to the school: curricula and goal standards imposed by the government. It partly sets the boundaries for didacticalpedagogical autonomy and collaborative activities. This may help explain the limited quantitative effect sizes as all of the identified profiles scored high on didactical-pedagogical autonomy.

Moreover, qualitative results provided more fine-grained insights into types of collaboration. Exchange activities can consist of more superficial exchanges (e.g., sharing teaching materials, making practical agreements) that are experienced as less invasive and can easily be combined with an individualistic interpretation of autonomy. Deep-level exchange activities and professional 
collaboration (e.g., discussing teaching practices and beliefs, jointly teaching) are less common and tend to challenge this conceptualisation. Teachers find a balance between autonomy and collaboration and demonstrate a collaborative attitude as long as they still have sufficient autonomy to do their own thing within their classroom. Furthermore, the fact that teachers often referred to collaboration as having to do things the same way and making agreements puts a strain on collaboration and may help explain why teachers sometimes feel that it can hinder their autonomy.

\section{Other Factors Influencing the Relationship Between Autonomy and Collaboration}

Finally, the qualitative results indicate that a lot of other factors play a role in the relationship between teachers' autonomy and willingness to collaborate, such as school structure, time, and having parallel colleagues.

Teachers reported structural constraints of collaboration and when teachers do not have any parallel colleagues this can result in constrained individualism where teachers feel isolated and lack support (Hargreaves, 1994). Teachers' focus on parallel colleagues as collaborative partners demonstrates how they often feel that disciplinary within-grade level collaboration is most important and interdisciplinary or vertical collaboration is less relevant. Moreover, structural constraints indicate that a reactive or individualistic attitude does not always reflect teachers' intrinsic desire for independence. This nuances the quantitative findings as a reactive attitude may both emanate from teachers' internal preference for independence or from external factors that - in teachers' experience hamper collaboration or make it less relevant (e.g., not having parallel colleagues). Furthermore, more experienced teachers are more likely to demonstrate a reactive attitude as they feel that they have built up enough expertise to work independently.

Moreover, the interviews indicated the importance of autonomy at the collaborative level. This is reflected in the different value teachers attach to top-down imposed versus spontaneous or bottomup collaboration. The biggest difference between both includes the perceived relevance of and need to collaborate that initiate bottom-up collaborative activities. The latter are perceived to be more relevant because of their close connection to classroom practice and the possibility to discuss issues just-intime. Moreover, in the case of bottom-up collaboration teachers choose partners based upon common 
professional and pedagogical beliefs (Leonard \& Leonard, 1999). This may provide teachers with a psychologically safe environment for discussing issues they feel are very personal (e.g., classroom teaching). However, when schools or principals want to foster teacher collaboration, they tend to impose formalised meeting structures and topics to be discussed or certain streamlining requirements such as the need to use the same exams. However, such administrative regulations attempting to force teachers to collaborate do not always result in a collaborative culture but may end up in contrived collegiality and superficial types of collaboration aimed at fulfilling assigned tasks (Datnow, 2011; Hargreaves \& Dawe, 1990). Teachers who argued to lack autonomy in collaboration felt more negative about collaborative work. Hence, to foster collaboration, it is important to allow teachers some degree of autonomy in how and when they collaborate and what issues they discuss.

\section{Towards a Refined Conceptual Framework}

Two refinements of current theorising on the relationship between teacher autonomy and collaboration are proposed: refining the domains of autonomy and different origins of collaboration.

In relation to (openness towards) collaboration didactical-pedagogical autonomy should be split up in two components. Teachers appear to be less sensitive regarding content-related aspects such as choice and use of textbooks, student evaluation, planning, and course materials. However, with regard to teaching methods/strategies, teaching style, and classroom management, classroom teaching-related aspects, teachers tend to be more sensitive. Hence, in relation to collaboration, three autonomy domains can be distinguished: (1) curricular autonomy (influenced mostly by higher-level institutions); (2) content-related didactical-pedagogical autonomy (mostly including a certain level of openness towards collaboration); and (3) classroom teaching-related didactical-pedagogical autonomy (including a higher level of sensitivity towards external influences). Hence, while the quantitative results demonstrate a unified collaborative attitude, qualitative findings indicate that a more nuanced perspective is required. This may relate to the level of depth of this collaborative attitude. A certain level of openness towards collaboration may present itself as a uniform teacher characteristic (some teachers having an overall higher/lower preference for collaboration). However, openness towards profound deep-level collaboration may be more strongly related to different autonomy domains. 
Furthermore, different levels of autonomy can be distinguished: individual autonomy and collaborative autonomy. The latter refers to the origin of teacher collaboration: Whether it is derived from external push factors (e.g., formalised top-down collaboration, collaboration in reaction to increased accountability, tendency towards streamlined education due to scaling up of education and schools) or internal pull factors (e.g., spontaneous collaboration derived from a perceived need to collaborate). Teachers' autonomy and attitude may be differently related to these different types of collaboration.

\section{Limitations and Strengths}

A first limitation of this study includes the fact that the quantitative analyses are focused on collaboration with subject group colleagues. However, given the focus on classroom autonomy and teacher collaboration on classroom or instruction-related issues, subject groups are meaningful collaborative entities, which was confirmed in the interviews. Teachers tend to collaborate with teachers in the same subject field because of the increased likelihood to have a common ground and experience shared teaching problems (Penuel et al., 2010; Yasumoto, Uekawa, \& Bidwell, 2001). Future research should investigate other types of collaboration, such as interdisciplinary collaboration or spontaneously rising informal collaboration structures. Secondly, only limited effect sizes were found in the quantitative analyses. The results of the qualitative analyses provide provisional explanations for these limited effects, raise points for discussion, and indicate avenues for future research. The latter should for example include methods that go beyond self-report (e.g., observation) as these phenomena have proven to be difficult to grasp. A third set of limitations derives from the setup of our mixed methods design. While quantitative results were used as input for the selection of participants for interviews, these findings were not used to generate additional interview questions for the different teacher profiles. This could have provided additional insights into the individuality of teachers' perceptions. Moreover, cases were not compared in the qualitative analyses based upon their quantitative scores. In the end the differences between the selected cases were less distinct as intended. Moreover, no clear patterns were found that would suggest that explanations strongly differed across cases based upon their quantitative selection criteria. Hence, the sampling strategies now served as a 
way to have a well-balanced sample for the interviews as our focus was on using qualitative findings to further contextualise and explain quantitative findings. Finally, given that school systems can strongly differ across countries and cultures, different results might be found in other contexts. Hence, an area for future research includes exploring the influence of characteristics of the school system and cultural features.

However, this study also has various strengths giving additional value to its results. First, by using a mixed methods approach, it is possible to investigate the relationship between autonomy and collaboration using rigorous statistical analyses on a large scale and look for a deeper-level understanding as the qualitative analyses provided much-needed nuances and additional insights. This study thus demonstrates how quantitative and qualitative analyses are mutually constitutive of a refined research design that provides more insights than they would to separately. Secondly, while previous research on this topic has focused on variable-centred analyses, this study added a personcentred approach. This was especially relevant to the investigation of teachers' autonomy attitude, which is specific to individual teachers. Person-centred analyses allowed investigating these patterns among teachers and assessing how different profiles occur in practice. As a possible limitation of person-centred analyses includes its empirically derived and potentially arbitrary nature, the fact that large sample sizes were used and that the profiles were validated in a second independent sample strengthens our findings. 


\section{References}

Author(s) (2015). [details removed for peer review]

Author(s) (2017a). [details removed for peer review]

Author(s) (2017b). [details removed for peer review]

Achinstein, B. (2002). Conflict amid community: The micropolitics of teacher collaboration. Teachers College Record, 104, 421-455. doi:10.111/1467-9620.00168

Bidwell, C. E. (1965). The school as a formal organization. In J. G. March (Ed.). The school as a formal organization. Chicago, IL: Rand McNally.

Brown, M. W., \& Cudeck, R. (1993). Alternative ways of assessing model fit. In A. Bollen, \& J. S. Long (Eds.), Testing structural equation models (pp. 136-162). California, CA: Sage Publications Inc.

Cheng, L. P. \& Ko, H. (2009). Teacher-team development in a school-based professional development program. The Mathematics Educator, 19, 8-17. Retrieved from http://tme.journals.libs.uga.edu/index.php/tme

Chirkov, V., Ryan, R. M., Kim, Y., \& Kaplan, U. (2003). Differentiating autonomy from individualism and independence: A self-determination theory perspective on internalization of cultural orientations and well-being. Journal of Personality and Social Psychology, 84, 97-110. doi:10.1037/0022-3514.84.1.97

Clement, M., \& Vandenberghe, R. (2000). Teachers' professional development: A solitary or collegial (ad)venture? Teaching and Teacher Education, 16, 81-101. doi:10.1016/S0742-051X(99)00051-7

Datnow, A. (2011). Collaboration and contrived collegiality: Revisiting Hargreaves in the age of accountability. Journal of Educational Change, 12, 147-158. doi:10.1007/s10833-011-9154-1

de Vries, S., Jansen, E. P. W. A., \& van de Grift, W. J. C. M. (2013). Profiling teachers' continuing professional development and the relation with their beliefs about learning and teaching. Teaching and Teacher Education, 33, 78-89. doi:10.1016/j.tate.2013.02.006

Deci, E. L., \& Ryan, R. M. (1991). Why we do what we do: The dynamics of personal autonomy. New York, NY: G.P. Putnam's Sons. 
DeCharms, R. (1968). Personal causation: The internal affective determinants of behaviour. New York, NY: Academic Press.

Desurmont, A., Forsthuber, B., \& Oberheidt, S. (2008). Levels of autonomy and responsibilities of teachers in Europe. Brussels, Belgium: Eurydice.

Doppenberg, J. J., den Brok, P. J., \& Bakx, A. W. E. A. (2012). Collaborative teacher learning across foci of collaboration: Perceived activities and outcomes. Teaching and Teacher Education, 28, 899-910. doi:10.1016/j.tate.2012.04.007

Firestone, W. A., \& Herriott, R. E. (1982). Two images of schools as organizations: An explication and illustrative empirical test. Educational Administration Quarterly, 18, 39-59. doi:10.1177/0013161X82018002004

Firestone, W. A., \& Pennell, J. R. (1993). Teacher commitment, working conditions, and differential incentive policies. Review of Educational Research, 63, 489-525. doi:10.3102/00346543063004489

Friedman, I. A. (1999). Teacher-perceived work autonomy: The concept and its measurement. Educational and Psychological Measurement, 59, 58-76. doi:10.1177/0013164499591005

Gajda, R., \& Koliba, C. J. (2008). Evaluating and improving the quality of teacher collaboration: A field-tested framework for secondary school leaders. NASSP Bulletin, 92, 133-153. doi: $10.1177 / 0192636508320990$

Gavrilyuk, O. A., Lakhno, A. V., Lebedeva, T. P., Zotin, A. G., Karelina, N. A., \& Kuzina, E. N. (2014). Autonomy in teaching: Escaping control or taking control? International Journal of Humanities Social Sciences and Education, 1(10), 135-142. doi:10.1.1.686.640

Goddard, Y. L., Goddard, R. D., \& Tschannen-Moran, M. (2007). A theoretical and empirical investigation of teacher collaboration for school improvement and student achievement in public elementary schools. Teachers College Record, 109, 877-896. Retrieved form http://tcrecord.org

Gore, J., Lloyd, A., Smith, M, Bowe, J., Ellis, H., \& Lubans, D. (2017). Effects of professional development on the quality of teaching: Results from a randomised controlled trial of Quality Teaching Rounds. Teaching and Teacher Education, 68, 99-113. doi:10/1016/j.tate.2017.08.007

Hargreaves, A. (1993). Individualism and individuality: Reinterpreting the teacher culture. 
International Journal of Educational Research, 19, 227-246.

Hargreaves, A. (1994). Changing teachers, changing times. Teachers' work and culture in the Postmodern Age. London, England: Cassell.

Hargreaves, A. (2010). Presentism, individualism, and conservatism: The legacy of Dan Lortie's Schoolteacher: A sociological study. Curriculum Inquiry, 40, 143-154. doi:10.1111/j.1467873X.200900472.x

Hargreaves, A., \& Dawe, R. (1990). Paths of professional development: Contrived collegiality, collaborative culture, and the case of peer coaching. Teaching and Teacher Education, 6, 227241. doi:10.1016/0742_051X(90)90015-W

Henry, K. L., \& Muthén, B. (2010). Multilevel latent class analysis: An application of adolescent smoking typologies with individual and contextual predictors. Structural Equation Modeling: A Multidisciplinary Journal, 17, 193-215. doi:10.1080/10705511003659342

Hodgins, H. S., Koestner, R., \& Duncan, N. (1996). On the compatibility of autonomy and relatedness. Personality and Social Psychology Bulletin, 22, 227-237. doi:10.1177/0146167296223001

Horn, I. S., Garner, B., Delinger Kane, B., \& Brasel, J. (2017). A taxonomy of instructional learning opportunities in teachers' workgroup conversations. Journal of Teacher Education, 68, 41-54. doi:10.1177/0022487116676315

Hu, L., \& Bentler, P. M. (1999). Cut-off criteria for fit indexes in covariance structure analysis: Conventional criteria versus new alternatives. Structural Equation Modeling, 6, 1-55. doi:10.1080/10705519909540118

Husband, R. E., \& Short, P. M. (1994). Interdisciplinary teams lead to greater teacher empowerment. Middle School Journal, 26, 58-60. doi:10.1080/00940771.1994.11494412

Ivankova, N. V., Creswell, J. W., \& Stick, S. L. (2006). Using mixed-methods sequential explanatory design: From theory to practice. Field Methods, 18, 3-20. doi:10.1177/1525822X05282260

Johnson, B. (2003). Teacher collaboration: Good for some, not so good for others. Educational Studies, 29, 337-350. doi:10.1080/0305569032000159651 
Kelchtermans, G. (2006). Teacher collaboration and collegiality as workplace conditions: A review. Zeitschrift für Pädagogik, 52, 220-237. Retrieved from http://pedocs.de

Kwakman, K. (2003). Factors affecting teachers' participation in professional learning activities. Teaching and Teacher Education, 19, 149-170. doi:10.1016/S0742-051X(02)00101-4

Lavié, J. M. (2006). Academic discourses on school-based teacher collaboration: Revisiting the arguments. Educational Administration Quarterly, 42, 773-805. doi:10.1177/0013161X06290647

Leech, N. L., \& Onwuegbuzie, A. J. (2009). A typology of mixed methods research designs. Quality \& Quantity, 43, 265-275. doi:10.1007/s11135-007-9105-3

Leonard, L. J., \& Leonard, P. E. (1999). Reculturing for collaboration and leadership. The Journal of Educational Research, 92, 237-242. doi:10.1080/00220679909597601

Levine, A. H., \& Marcus, A. S. (2007). Closing the achievement gap through teacher collaboration: Facilitating multiple trajectories of teacher learning. Journal of Advanced Academics, 19, 116138. doi:10.4219/jaa-2007-707.

Levine, A. H., \& Marcus, A. S. (2010). How the structure and focus of teachers' collaborative activities facilitate and constrain teacher learning. Teaching and Teacher Education, 26, 389-398. doi:10.1016/j.tate.2009.03.001

Little, J. W. (1990). The persistence of privacy: Autonomy and initiative in teachers' professional relations. Teachers College Record, 91, 509-536. Retrieved from https://eric.ed.gov/?id=EJ412496

Lortie, D. (1975). Schoolteacher: A sociological study. Chicago, IL: University of Chicago Press.

Lubke, G. H., \& Muthén, B. (2005). Investigating population heterogeneity with factor mixture models. Psychological Methods, 10, 21-39. doi:10.1037/1082-989X.10.1.21

Moolenaar, N. M. (2010). Ties with potential: Nature, antecedents, and consequences of social networks in school teams (Doctoral dissertation). Retrieved from http://dare.uva.nl

Moomaw, W. E. (2005). Teacher-perceived autonomy: A construct validation of the teacher autonomy scale (Doctoral dissertation, University of West Florida). Retrieved from http://etd.fcla.edu/WF/WFE0000027/Moomaw_William_Edward_200512_EdD.pdf 
O’Reilly, C. A., Chatman, J., \& Caldwell, D. F. (1991). People and organizational culture: A profile comparison approach to assessing person-organization fit. Academy of Management Journal, 34, 487-516. doi:10.2307/256404

Ohlsson, J. (2013). Team learning: Collective reflection processes in teacher teams. The Journal of Workplace Learning, 25, 296-309. doi:10.1108/JWL-Feb-2012-0011.

Parish, R., \& Arends, R. (1983). Why innovative programs are discontinued. Educational Leadership, 40, 62-65. Retrieved from http://www.ascd.org/ASCD/pdf/journals/ed_lead/el_198301_parish.pdf

Pearson, L. C., \& Moomaw, W. (2005). The relationship between teacher autonomy and stress, work satisfaction, empowerment, and professionalism. Educational Research Quarterly, 29, 38-54. Retrieved from http://eric.ed.gov/?id=EJ718115

Penuel, W. R., Riel, M., Joshi, A., Pearlman, L., Kim, C. M., \& Frank, K. A. (2010). The alignment of informal and formal organizational supports for reform: Implications for improving teaching in schools. Educational Administration Quarterly, 46, 57-95. doi:10.1177/1094670509353180

Plauborg, H. (2009). Opportunities and limitations of learning within teachers' collaboration in teams: Perspectives from action learning. Action Learning: Research and Practice, 6, 25-34. doi:10.1080/14767330902731293

Roller, M. R., \& Lavrakas, P. J. (2015). Chapter six: Qualitative content analysis. In M. R. Roller \& P. J. Lavrakas (Eds.), Applied Qualitative Research Design: A Total Quality Framework Approach (pp. 230-283). New York, NY: Guilford Press.

Sehgal, P., Nambudiri, R., Kumar Mishra, S. (2017). Teacher effectiveness through self-efficacy, collaboration and principal leadership. International Journal of Educational Management, 31, 505-517. doi:10.1108/IJEM-05-2016-0090

Siciliano, M. D. (2016). It's the quality not the quantity of ties that matters: Social networks and selfefficacy beliefs. American Educational Research Journal, 53, 227-262. doi:10.3102/0002831216629207

Simbula, S., Guglielmi, D., \& Schaufeli, W. B. (2011). A three-wave study of job resources, selfefficacy, and work engagement among Italian schoolteachers. European Journal of Work and Organizational Psychology, 20, 285-304. doi:10.1080/13594320903513916 
Street, M. S., \& Licata, J. W. (1989). Supervisor expertise: Resolving the dilemma between bureaucratic control and teacher autonomy. Planning and Changing, 20, 97-107. Retrieved from http://eric.ed.gov/ ?id=EJ403762

Strong, L. E. G., \& Yoshida, R. K. (2014). Teachers' autonomy in today's educational climate: Current perceptions from an acceptable instrument. Educational Studies: A Journal of The American Educational Studies Association, 50, 123-145. doi:10.1080/00131946.2014.880922

Tjosvold, D., \& Yu, Z. (2007). Group risk taking: The constructive role of controversy in China. Group Organization Management and Administration, 34, 47-62. doi:10.1177/1059601106287110

Visscher, A. J., \& Witziers, B. (2004). Subject departments as professional communities? British Educational Research Journal, 30, 785-800. doi:10.1080/0141192042000279503

Yasumoto, J. Y., Uekawa, K., \& Bidwell, C. E. (2001). The collegial focus and high school students' achievement. Sociology of Education, 74, 181-209. doi:10.2307/2673274

Yu-Hong, J., \& Ting, M. (2012). A review of the research on language teacher autonomy, Sino-US English Teaching, 9, 1045-1055. doi:2012060381977777

Wall, M. M., Guo, J. \& Amemiya, Y. (2012). Mixture factor analysis for approximating a nonnormaly distributed continuous latent factor with continuous and dichotomous observed variables. Multivariate Behavioral Research, 47, 276-313. doi:10.1080/00273171.2012.658339

Wermke, W., \& Höstfält, G. (2014). Contextualizing teacher autonomy in time and space: A model for comparing various forms of governing the teaching profession. Journal of Curriculum Studies, 46, 58-80. doi:10.1080/00220272.2013.812681

Westheimer, J. (2008). Learning among colleagues: Teacher community and the shared enterprise of education. In M. Cochran-Smith, S., Feiman-Nemser, \& J. McIntyre (Eds.), Handbook of research on teacher education (pp. 756-782). Reston, VA and Lanham, MD: Association of Teacher Educators and Rowman.

Wilches, J. (2007). Teacher Autonomy: A Critical Review of the Research and Concept beyond Applied Linguistics. Íkala, Revista de Lenguaje y Cultura, 12(18), 245-275. Retrieved from http://aprendeenlinea.udea.edu.co/revistas/index.php/ikala/article/view/2720 
Willner, R. G. (1990). Images of the future now: Autonomy, professionalism, and efficacy (Doctoral dissertation). Retrieved from http://fordham.bepress.com/dissertations/AAI9123118/ 
Appendix A

ICC Values

\begin{tabular}{ccccccc}
\hline & \multicolumn{3}{c}{ Subject group ICC } & \multicolumn{3}{c}{ School ICC } \\
& Mean & Min & Max & Mean & Min & Max \\
\hline $\begin{array}{c}\text { Didactical-pedagogical } \\
\text { autonomy }\end{array}$ & & & & & & \\
Sample 1 & .054 & .023 & .097 & .015 & .003 & .023 \\
Sample 2 & .059 & .026 & .125 & .025 & .013 & .050 \\
Curricular autonomy & & & & & & \\
Sample 1 & .094 & .060 & .118 & .001 & .001 & .028 \\
Sample 2 & .124 & .095 & .140 & .007 & .001 & .014 \\
Collaborative attitude & & & & & & \\
Sample 1 & .084 & .005 & .131 & .020 & .005 & .033 \\
Sample 2 & .106 & .007 & .153 & .017 & .007 & .034 \\
Exchange activities & & & & & & \\
Sample 1 & .058 & .031 & .080 & .013 & .001 & .028 \\
Sample 2 & .080 & .038 & .155 & .013 & .002 & .021 \\
Professional collaboration & & & & & & \\
Sample 1 & .159 & .100 & .252 & .038 & .021 & .054 \\
Sample 2 & .181 & .092 & .312 & .026 & .001 & .071 \\
Constructive conflict & & & & & & .025 \\
Sample 1 & .063 & .046 & .076 & .023 & 0 & .001 \\
Sample 2 & .017 & .017 & .017 & .001 & 0 & \\
\hline
\end{tabular}


Appendix B

Coding Tree Interview Analyses

\section{AUTONOMY}

- Autonomy - Subject group

- Desired autonomy

- Downsides of autonomy

- Evolution of autonomy

- Changes in context

- Experience

- Experienced autonomy

- Factors influencing autonomy

- Gender

- Facilitating factors autonomy

- Factors inhibiting autonomy

- Parallel colleague(s)

- Principal/School administration

- Meaning of autonomy

- School culture

- Type of autonomy

- Curricular autonomy

- Didactical-pedagogical autonomy

- Value of autonomy
- Adapt to student needs
- Be yourself
- Motivation
- Teacher as professional
- General importance

\section{COLLABORATION}

- Collaboration - Subject group

- Parallel colleague(s)

- Collaborative attitude

- Downsides of collaboration

- Evolution of collaboration

- Frequency of collaboration

- Facilitating factors collaboration
- Appreciation of effort
- Gender
- Generation differences
- Goal oriented collaboration
- Experience/skills
- Group composition features
- Horizontal organisation
- Psychological safety
- Reciprocity of collaboration 
- Social connection / personality

- Student needs

- Team identification

- Factors inhibiting collaboration
$\circ$ Alignment
$\circ$ Age
○ Disagreement
- Formality
- Formation of subgroups
- Hierarchy
- Lack of collaborative attitude
- Lack of reciprocity
- Lack of social connection / Personality
- Negative social dynamics
- Practical issues
- Short term appointment
- Teacher efficacy
- Teamwork skills

- School-level influences

- Principal / School administration

- School culture

- School infrastructure

- Type of collaboration

- Collaborative activities

- Exchange activities

- Distribution of tasks

- Professional collaboration

- Constructive conflict

- Formal-informal collaboration

- School-level participation

- Top-down collaboration

- Vertical-horizontal collaboration

- Value of collaboration

\section{AUTONOMY-COLLABORATION}

- Balance

- Tensions

- Interest of the student

- Team autonomy 


\section{Appendix C}

Results (Multilevel) Factor Mixture Models

\begin{tabular}{|c|c|c|c|c|}
\hline Model & \multicolumn{4}{|c|}{ Number of level 1 profiles } \\
\hline \multicolumn{5}{|l|}{$\begin{array}{l}\text { Sample } 1 \\
\text { 1. Fixed effects model }\end{array}$} \\
\hline $\begin{array}{l}\text { No. of free } \\
\text { parameters }\end{array}$ & 66 & 70 & 74 & 78 \\
\hline Log-likelihood & -44291.65 & -44188.55 & -44102.54 & -44076.12 \\
\hline $\mathrm{aBIC}$ & 88860.97 & 88671.60 & 88516.41 & 88480.41 \\
\hline Entropy & 1 & .839 & .772 & .700 \\
\hline \multicolumn{5}{|c|}{ 2. Random effects parametric model } \\
\hline $\begin{array}{l}\text { No. of free } \\
\text { parameters }\end{array}$ & & 71 & 76 & 81 \\
\hline Log-likelihood & & -44168.63 & -44076.22 & -44044.55 \\
\hline $\mathrm{aBIC}$ & & 88635.96 & 88472.18 & 88429.89 \\
\hline Entropy & & .814 & .755 & .745 \\
\hline \multicolumn{5}{|l|}{ Sample 2} \\
\hline \multicolumn{5}{|l|}{ 1. Fixed effects model } \\
\hline $\begin{array}{l}\text { No. of free } \\
\text { parameters }\end{array}$ & 66 & 70 & 74 & 78 \\
\hline Log-likelihood & -39452.66 & -39336.12 & -39253.50 & -39232.50 \\
\hline $\mathrm{aBIC}$ & 79174.17 & 78957.36 & 78808.42 & 78782.71 \\
\hline Entropy & 1 & .807 & .804 & .777 \\
\hline 2. Random effects pa & ic model & & & \\
\hline $\begin{array}{l}\text { No. of free } \\
\text { parameters }\end{array}$ & & 71 & 76 & 81 \\
\hline Log-likelihood & & -39320.93 & -39224.11 & -39193.68 \\
\hline $\mathrm{aBIC}$ & & 78931.06 & 78757.79 & 78717.30 \\
\hline Entropy & & .838 & .794 & .780 \\
\hline
\end{tabular}

